\title{
DNA nucleic acid sequence-based amplification-based genotyping for polymorphism analysis
}

Cecile Berard, Marie-Angélique Cazalis, Philippe Leissner, and Bruno Mougin

bioMérieux, Marcy l'Etoile, France

BioTechniques 37:680-686(October 2004)

Nucleic acid sequence-based amplification (NASBA) is a sensitive isothermal transcriptionbased amplification method known to be a suitable tool for RNA research. We demonstrate that NASBA technology can be applied to single nucleotide polymorphism (SNP) analysis using human genomic DNA as a template. Combination of DNA NASBA with multiplex hybridization of specific molecular beacons makes it possible to unambiguously discriminate the presence of the SNP of interest. This protocol is easy-to-use, robust, and makes it possible to rapidly detect single nucleotide substitutions in clinical or cell line DNA sequences using a large range of DNA input. Such a real-time genotyping DNA NASBA assay can find broad application in clinical diagnostics.

\section{INTRODUCTION}

Single nucleotide polymorphisms (SNP) represent the largest source of diversity in the human genome. Some of these variations have been directly linked to human diseases, though nearly all are neutral. Usually, the mutation is detected after or during PCR amplification of the region of interest using specific labeled probes such as molecular beacons (1-6). Indeed, molecular beacons are uniquely suited for SNP analysis because they recognize their targets with significantly higher specificity than conventional oligonucleotide probes (7-10).

Nucleic acid sequence-based amplification (NASBA) is a sensitive and efficient isothermal transcription-based amplification method specifically designed for the detection of RNA targets (11). NASBA has proved successful in the detection of various messenger RNAs (mRNAs) and in the detection of viral, bacterial, and fungal RNA in clinical samples and food (12-19). Furthermore, this technology has also been described as capable of amplifying DNA with or without a denaturation step in the process $(11,20,21)$. Here we describe a DNA NASBA-based protocol for analyzing SNP from DNA as the sole template. DNA NASBA results in the production of large amounts of single-stranded antisense RNA that can be detected through the hybridization of specific fluorescent molecular beacons. Using Factor V Leiden (G1691 A) mutation as a model (22), we propose a real-time DNA NASBA-based assay that allows simple, clear, and fast discrimination of SNPs in genomic DNA extracted from cell lines and clinical samples.

\section{MATERIALS AND METHODS}

\section{Plasmid DNA}

Based on template DNA genotyped for Factor V Leiden, 374-bp fragments containing either the $\mathrm{G}$ or A nucleotide at position 1691 were generated by PCR using forward (5'-AGTGCTTAACAAGACCATACTA-3') and reverse (5'-AACAGACCTGGAATTTGAAACTAA-3') primers located at position 36568-36589 and 36918-36941, respectively (GenBank ${ }^{\circledR}$ accession no. NT_004668). PCR amplification was performed in a Model 9600 thermal cycler (Perkin-Elmer, Wellesley, MA, USA) $\left(2 \mathrm{~min}\right.$ at $95^{\circ} \mathrm{C} ; 30$ cycles of 30 s at $95^{\circ} \mathrm{C}, 30 \mathrm{~s}$ at $55^{\circ} \mathrm{C}, 30 \mathrm{~s}$ at $72^{\circ} \mathrm{C}$; followed by $7 \mathrm{~min}$ at $72^{\circ} \mathrm{C}$ ). The two PCR fragments were cloned into the PCR-Trap vector (GeneHunter) and verified by sequencing. Plasmids carrying the G1691G or A1691A genotype were amplified and purified using the Plasmid Maxi Kit (Qiagen, Hilden, Germany) as recommended by the manufacturer.

\section{Cell Line Culture and Genomic DNA Extraction}

Three lymphoblastoid cell lines of known Factor V (G1691A) genotype were used in the study: $(i)$ GM14899 cells carrying the A1691A genotype; (ii) GM16000C cells carrying the G1691G genotype; and (iii) GM16028B cells carrying the heterozygous G1691A genotype. All cell lines were purchased from Coriell Cell Repositories (Camden, NJ, USA). Cell lines were grown in RPMI 1640 supplemented with $15 \%$ fetal bovine serum, 2 $\mathrm{mM} \mathrm{L}$-glutamine, and $0.2 \mu \mathrm{g} / \mu \mathrm{L}$ penicillin-streptomycin at $37^{\circ} \mathrm{C}$ in a $5 \%$ $\mathrm{CO}_{2}$ atmosphere. Genomic DNA was extracted by treating the cellular pellet with $0.1 \mu \mathrm{g} / \mu \mathrm{L}$ proteinase $\mathrm{K}$ for $12 \mathrm{~h}$ followed by a phenol/chloroform step and ethanol precipitation. The genomic DNA was then recovered in $500 \mu \mathrm{L}$ of DNase-free water. DNA quality and quantity were determined on ethidium bromide-stained agarose gel and by UV spectrophotometry. Genomic DNA samples were stored at $-20^{\circ} \mathrm{C}$ until use.

\section{Clinical Samples and Genomic DNA Extraction}

Two hundred microliters of whole blood was collected in EDTA tubes from three individuals of known Factor V (G1691A) genotype. Genomic DNA was extracted using the $\mathrm{Nu}$ cleoSpin ${ }^{\circledR}$ Kit (Marcherey-Nagel, Hoerdt, France). Genomic DNA was then recovered in $20 \mu \mathrm{L}$ of DNase-free water. DNA quality and quantity were determined on ethidium bromide-stained agarose gel and by UV spectrophotometry. Genomic DNA samples were stored at $-20^{\circ} \mathrm{C}$ until use.

\section{DNA NASBA}

NASBA is based on the activity of 
avian myeloblastosis virus (AMV) reverse transcriptase (RT), Escherichia coli $\mathrm{RNase} \mathrm{H}$ and T7 RNA polymerase with two oligonucleotide primers to amplify the desired fragment more than $10^{12}$-fold in $90 \mathrm{~min}$ (20). Briefly, based on the NucliSens ${ }^{\circledR}$ Basic Kit (bioMérieux bv, Boxtel, The Netherlands), $5 \mu \mathrm{L}$ genomic DNA were added to $10 \mu \mathrm{L}$ of NASBA buffer [final concentration in a $20-\mu \mathrm{L}$ reaction mixture: $40 \mathrm{mM}$ Tris$\mathrm{HCl}, \mathrm{pH} 8.5,12 \mathrm{mM} \mathrm{MgCl} 2,70 \mathrm{mM}$ $\mathrm{KCl}, 5 \mathrm{mM}$ dithiothreitol, $15 \%$ (v/v) dimethylsulfoxide (DMSO), $1 \mathrm{mM}$ of each dNTP, $2 \mathrm{mM}$ of each NTP, 0.2 $\mu \mathrm{M}$ of each primers, $0.2 \mu \mathrm{M}$ of Factor $\mathrm{V}$ (1691-G) molecular beacon, and 0.1 $\mu \mathrm{M}$ of Factor V (1691-A) molecular beacon] and pre-incubated at $95^{\circ} \mathrm{C}$ for $2 \mathrm{~min}$ before incubation at $41^{\circ} \mathrm{C}$ for 2 min. Five microliters of enzyme mixture (0.08U RNase H, 32 U T7-RNA polymerase, $6.4 \mathrm{U} \mathrm{RT}$ ) were added, and the reaction was incubated at $41^{\circ} \mathrm{C}$ for $90 \mathrm{~min}$. Primer sets used for the amplification and molecular beacon sequences are shown in Table 1.

\section{Real-Time NASBA Detection of the SNP}

Real-time detection of NASBA products was performed by NucliSens EasyQ Analyzer (bioMérieux bv) using molecular beacons that are DNA oligonucleotides labeled with FAM (6-carboxy-fluoroscein) or ROX (6-carboxy-
X-rhodamine) fluorophores at the $5^{\prime}$ end and a quencher (Dabsyl) at the $3^{\prime}$ end. Probes were synthesized by Eurogentec (Seraing, Belgium). Molecular beacons hybridize with the amplicon during amplification, and emitted fluorescence is measured every $45 \mathrm{~s}$, allowing real-time detection.

Detection of the polymorphic nucleotide was performed by mixing molecular beacons specific to the $G$ or A nucleotide in the same tube. Based on the raw fluorescent signal data, the open/closed $(\mathrm{O} / \mathrm{C})$ signal ratio of the hybridization reaction, corresponding to the ratio between the end point signal value determined at $90 \mathrm{~min}$ and the background signal value at $45 \mathrm{~s}$, can be determined for each molecular probe. Therefore, for each genotyping assay, the $\mathrm{O} / \mathrm{C}$ signal ratio of both $\mathrm{G}$ and $\mathrm{A}$ probes was automatically calculated by the software of the NucliSens EasyQ Analyzer, thus clearly discriminating the genotype of the DNA tested.

\section{RESULTS AND DISCUSSION}

We have reported here that NASBA, which is known to be a suitable tool for RNA research, can be adapted to amplify DNA for genotyping application if a preliminary denaturation step is added in the process. Indeed, when denaturing purified genomic DNA at $95^{\circ} \mathrm{C}$ for 2 min, amplification primers can an-

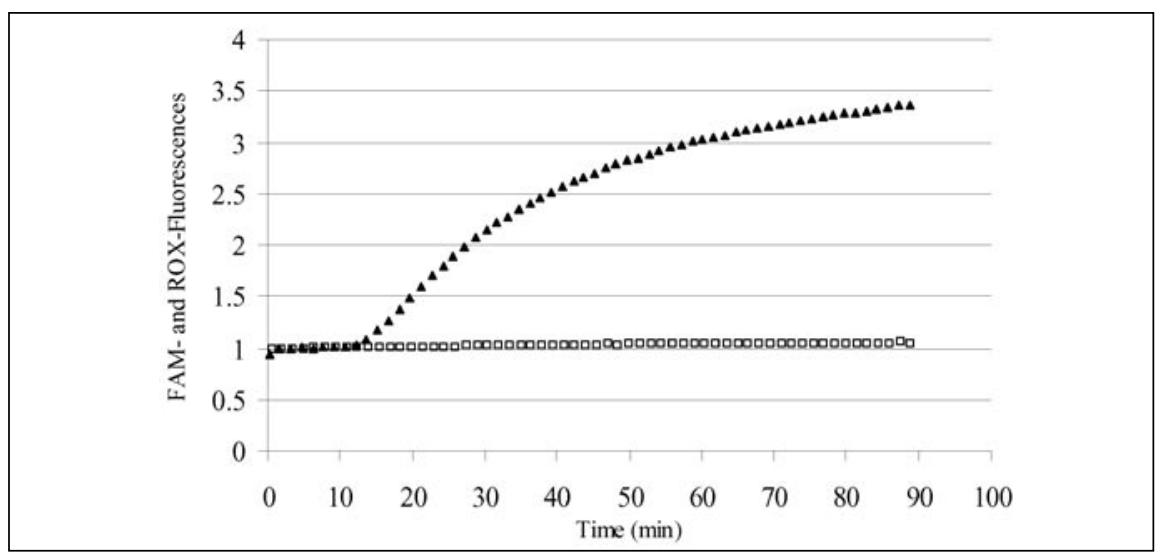

Figure 1. Multiplex detection of the Factor $\mathrm{V}$ Leiden allele in a real-time nucleic acid sequencebased amplification (NASBA) reaction using $50 \mathrm{ng}$ plasmid DNA carrying the Factor V (A1691A) genotype. Two differently colored molecular beacons were present in the reaction. Each kinetics curve is depicted using the symbol of the corresponding molecular beacon used [ROX-labeled G-specific probe $(\square)$ and FAM-labeled A-specific probe $(\boldsymbol{\Delta})$ ]. No fluorescence was observed using either the FAM- or the ROX-labeled molecular beacon in a control reaction containing only water (data not shown). Amplification plots are representative of triplicate experiments. 
neal to the single strand target and initiate the NASBA process. When combining this amplification process with a hybridization and detection step using specific fluorescent molecular beacons, SNP can be detected in real-time with the NucliSens EasyQ Analyzer.

We first tested the amplification efficacy and hybridization specificity of

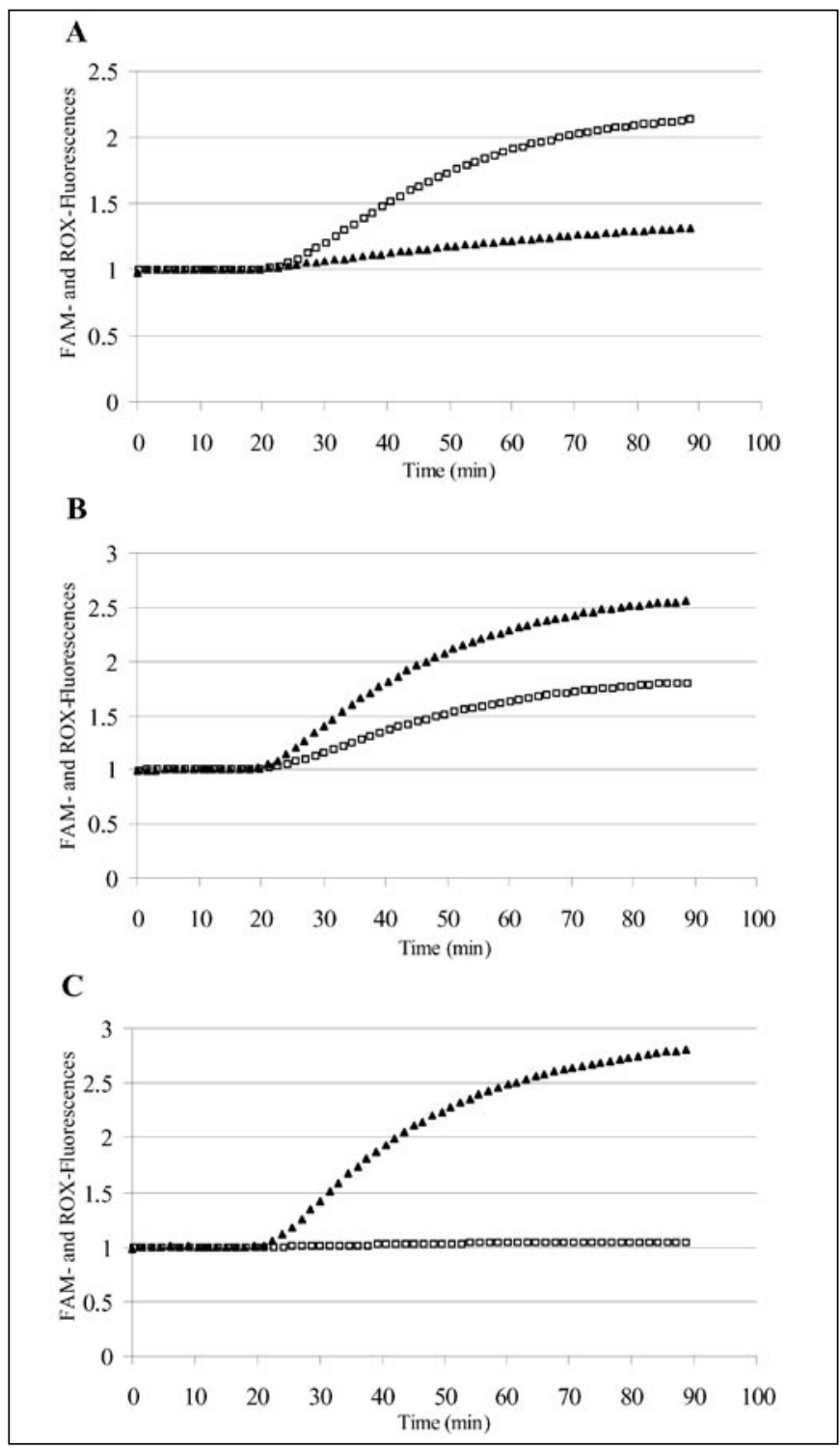

Figure 2. Multiplex detection of the Factor $V$ Leiden allele in a realtime nucleic acid sequence-based amplification (NASBA) reaction using 50 ng genomic DNA extracted from cell lines carrying (A) the Factor $V$ (G1691G) genotype, (B) the Factor V (G1691A) genotype, and (C) the Factor V (A1691A) genotype. Two differently colored molecular beacons were present in each reaction. Each kinetics curve is depicted using the symbol of the corresponding molecular beacon used [ROX-labeled G-specific probe ( $\square$ ) and FAM-labeled A-specific probe $(\boldsymbol{\Delta})$ ]. No fluorescence was observed using either the FAM- or the ROX-labeled molecular beacon in a control reaction containing only water (data not shown). Amplification plots are representative of triplicate experiments. molecular beacons on plasmid DNA samples. As shown in Figure 1, using 50 ng of Factor V (A1691A) plasmid, sositive signal with the probe, showing that NASBA technology is well-suited to amplifying pure DNA with no RNA contamination. Similar results were obtained with the Factor $\mathrm{V}$ (G1691G) plas- mid (data not shown). We then tested $50 \mathrm{ng}$ of genomic DNA extracted from three lymphoblastoid cell lines carrying either homozygous $\mathrm{G}$ or heterozygous or homozygous A genotype for the Factor $\mathrm{V}$ gene at position +1691 . We observed that the DNA carrying a homozygous (G1691G) genotype generated a positive signal with the $G$ molecular beacon and only a weak fluorescent signal with the A probe (Figure 2A). Heterozygous (G1691A) DNA generated a positive signal with both the $G$ and the

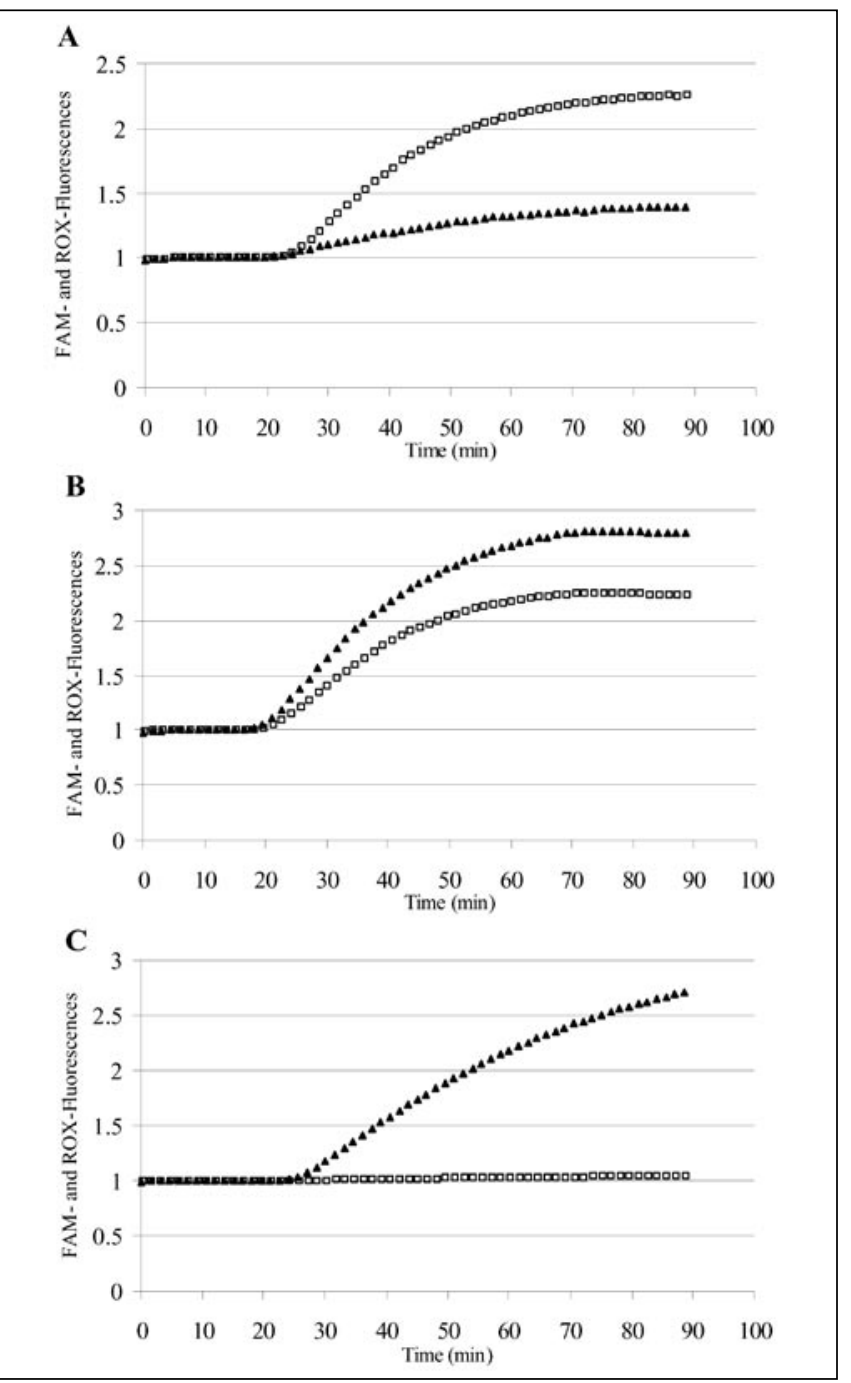

Figure 3. Multiplex detection of the Factor $V$ Leiden allele in real-time nucleic acid sequence-based amplification (NASBA) reaction using $3 \mu \mathrm{L}$ genomic DNA extracted from blood samples from individuals with (A) the Factor V (G1691G) genotype, (B) the Factor V (G1691A) genotype, and $(C)$ the Factor V (A1691A) genotype. Each kinetics curve is depicted using the symbol of the corresponding molecular beacon used [ROX-labeled G-specific probe $(\square)$ and FAM-labeled A-specific probe $(\boldsymbol{\Delta})]$. No fluorescence was observed using either the FAM- or the ROX-labeled molecular beacon in a control reaction containing only water (data not shown). Amplification plots are representative of triplicate experiments. 
Table 1. Sequences of the Primers and Molecular Beacons Used for Factor V Leiden Genotyping

\begin{tabular}{|llc|}
\hline Primer & Sequence & Position \\
\hline P1(T7) & 5'-aattctaatacgactcactatagggagaAAATTCTCAGAATTTCTGAAAGG-3' $^{\prime}$ & $36704-36726$ \\
P2 & 5'-AGTGCTTAACAAGACCATACTA-3' $^{\prime}$ & $36568-36589$ \\
$\begin{array}{l}\text { Molecular } \\
\text { Beacon }\end{array}$ & Sequence & \\
\hline $\begin{array}{l}\text { +1691-G } \\
\text { +1691-A }\end{array}$ & 5'-ROX-cgatcg CTGGACAGGCGAIGAAcgatcg-Dabsyl-3' & Position \\
\hline $\begin{array}{l}\text { The 3' antisense primer is elongated with a T7-promotor recognition sequence indicated in lowercase characters. The } \\
\text { stem sequences of the molecular beacons are indicated in lowercase italic characters. The positions are in reference to } \\
\text { the GenBank accession no. NT_004668. }\end{array}$ & $36663-36678$ \\
\hline
\end{tabular}

it allows mutations to be detected in 90 min. In conclusion, we propose a real-time DNA NASBA protocol that allows simple, clear, and rapid discrimination of single nucleotide substitutions in DNA sequences and that could find broad application in clinical diagnostics.

\section{ACKNOWLEDGMENTS}

We thank B. Deiman and F. Venema for their helpful input and Prof. Negrier and Dr. Vinciguerra (Hemostasis Laboratory of the Faculty of Lyon School of Medicine) for providing clinical samples.

\section{COMPETING INTERESTS STATEMENT}

The authors declare no conflicts of interest.

\section{REFERENCES}

A probes (Figure 2B), while homozygous (A1691A) DNA generated a positive signal with the A probe and only a background fluorescent signal with the $\mathrm{G}$ probe (Figure 2C). The O/C signal value confirmed the specificity of the hybridization of those probes and was thus helpful for discriminating between the two alleles (Table 2).

Successful genotyping was similarly observed when using $3 \mu \mathrm{L}$ of genomic DNA extracted from $200 \mu \mathrm{L}$ of clinical blood samples. Homozygous and heterozygous DNA were clearly identified (Figure 3, A-C). Again, the O/C signal values confirmed the discrimination among the different haplotypes (Table 2). Based on 200 clinical blood samples, we confidently determined that an $\mathrm{O} / \mathrm{C}$ ratio, for the 1691-A molecular beacon, higher than 1.5 was always associated with the presence of the A nucleotide at position 1691 . The presence of a $G$ at position 1691 was also associated with an $\mathrm{O} / \mathrm{C}$ ratio of the $1691-\mathrm{G}$ molecular beacon higher than 1.5 (data not shown). A range of $50 \mathrm{ng}$ to $1 \mu \mathrm{g}$ genomic DNA input per assay was successfully tested (data not shown), suggesting that the detection is robust with a large range of DNA input. This will be particularly useful in laboratories that perform highthroughput genotyping. In addition, we have shown that two standard extraction-purification protocols (i.e., phenol/ chloroform and commercial columnbased methods) give good genotyping results.

Altogether, our results demonstrate for the first time that NASBA technology using human genomic DNA as a template can be applied to SNP analysis. Combination of DNA NASBA and molecular beacons makes it possible to unambiguously discriminate the presence of the SNP of interest in real-time, using the NucliSens EasyQ Analyzer. Unlike $\mathrm{PCR}$, in which a thermal cycler is required, the isothermal nature of NASBA allows to minimize the instrumentation requirements for such genotyping assays. In addition, detection of the single-stranded RNA product of NASBA by probe-based hybridization does not require a denaturing step as needed with PCR. By determining an $\mathrm{O} / \mathrm{C}$ ratio threshold for each sequence, SNP detection can be automated with respect to the fluorescent signals generated. This protocol is easy-to-use and rapid, since
1.Giesendorf, B., J. Vet, S. Tyagi, E. Mensink, F. Trijbels, and H. Blom. 1998. Molecular beacons: a new approach for semi-automated mutation analysis. Clin. Chem. 44:482-486.

2.Kostrikis, L., Y. Huang, J. Moore, S. Wolinsky, L. Zhang, Y. Guo, L. Deutsch, J. Phair, et al. 1998. A chemokine receptor CCR2 allele delays HIV-1 disease progression and is associated with a CCR5 promoter mutation. Nat. Med. 4:350-353.

3.Gonzalez, E., M. Bamshad, N. Sato, S. Mummidi, R. Dhanda, G. Catano, S. Cabrera, M. McBride, et al. 1999. Race-specific HIV1 disease-modifying effects associated with CCR5 haplotypes. Proc. Natl. Acad. Sci. USA 96:12004-12009.

4.Hu, X., B. Belachew, L. Chen, H. Huang, and J. Zhang. 2000. Fluorescence-based single tube assays to rapidly detect human gene mutations. Strategies 13:71-73.

5.Johnson, M., L. Haupt, and L. Griffiths. 2004 Locked nucleic acid (LNA) single nucleotide polymorphism (SNP) genotype analysis and validation using real-time PCR. Nucleic Acids Res. 32:e55.

6.Shi, M., D. Caprau, J. Dagle, L. Christiansen, K. Christensen, and J. Murray. 2004. Application of kinetic polymerase chain reaction and molecular beacon assays to pooled analyses and high-throughput genotyping for candidate genes. Birth Defects Res. Part A Clin. Mol. Teratol. 70:65-74

7.Tyagi, S., D. Brattu, and F. Kramer. 1998. Multicolor molecular beacons for allele discrimination. Nat. Biotechnol. 16:49-53. 
8.Marras, S., F. Kramer, and S. Tyagi. 1999. Multiplex detection of single-nucleotide variations using molecular beacons. Genet. Anal. 14:151-156.

9.Marras, S., F. Kramer, and S. Tyagi. 2003. Genotyping SNPs with molecular beacons. Methods Mol. Biol. 212:111-128.

10.Tyagi, S., S. Marras, and F. Kramer. 2000. Wavelength-shifting molecular beacons. Nat. Biotechnol. 18:1191-1196.

11.Deiman, B., P. van Aarle, and P. Sillekens. 2002. Characteristics and applications of nucleic acid sequence based amplification (NASBA). Mol. Biotechnol. 20:163-179.

12.Darke, B., S. Jackson, S. Hanna, and J. Fox. 1998. Detection of human TNF-alpha mRNA by NASBA. J. Immunol. Methods 21:19-28.

13.Birch, L., C. Dawson, J. Cornett, and J. Keer. 2001. A comparison of nucleic amplification techniques for the assessment of bacterial viability. Lett. Appl. Microbiol. 33:296-301.

14.Borst, A., J. Verhoef, E. Boel, and A. Fluit. 2002. Clinical evaluation of a NASBA-based assay for detection of Candida spp. in blood and blood cultures. Clin. Lab. 48:487-492.

15.Polstra, A.M., J. Goudsmit, and M. Cornelissen. 2002. Development of real-time NASBA assays with molecular beacon detection to quantify mRNA coding for HHV-8 lytic and latent genes. BMC Infect. Dis. 2:1-10.
16.Cook, N. 2003. The use of NASBA for the detection of microbial pathogens in food and environmental samples. J. Microbiol. Methods 53:165-174.

17.Hibbitts, S., A. Rahman, R. John, D. Westmoreland, and J. Fox. 2003. Development and evaluation of NucliSens basic kit NASBA for diagnosis of parainfluenza virus infection with 'end-point' and 'real-time' detection. J. Virol. Methods 108:145-155.

18.Gore, H., C. Wakeman, R. Hull, and J. McKillip. 2003. Real-time molecular beacon NASBA reveals hblC expression from Bacillus spp. in milk. Biochem. Biophys. Res. Commun. 311:386-390.

19.Guichon, A., H. Chiparelli, A. Martinez, C. Rodriguez, A. Trento, J. Russi, and G. Carballal. 2004. Evaluation of a new NASBA assay for the qualitative detection of hepatitis C virus based on the NucliSens Basic Kit reagents. J. Clin. Virol. 29:84-91.

20.Compton, J. 1991. Nucleic acid sequence-based amplification. Nature 350:91-92.

21.Voisset, C., B. Mandrand, and G. ParanhosBaccalà. 2000. RNA amplification technique NASBA also amplifies homologous plasmid DNA in non-denaturing conditions. BioTechniques 29:236-240.

22.Bertina, R., B. Koeleman, T. Koster, F. Rosendaal, R. Dirven, H. de Ronde, P. van der Velden, and P. Reitsma. 1994. Mutation in blood coagulation factor $\mathrm{V}$ associated with resistance to activated protein C. Nature 369:64-67.

Received 5 April 2004; accepted 24 May 2004.

Address correspondence to Philippe Leissner, Human Genetics Department, bioMérieux, 69280 Marcy l'Etoile, France. e-mail: philippe.leissner@eu.biomerieux.com 